\title{
Qualified \\ Dublin Core and the \\ Digital Repository of Ireland
}
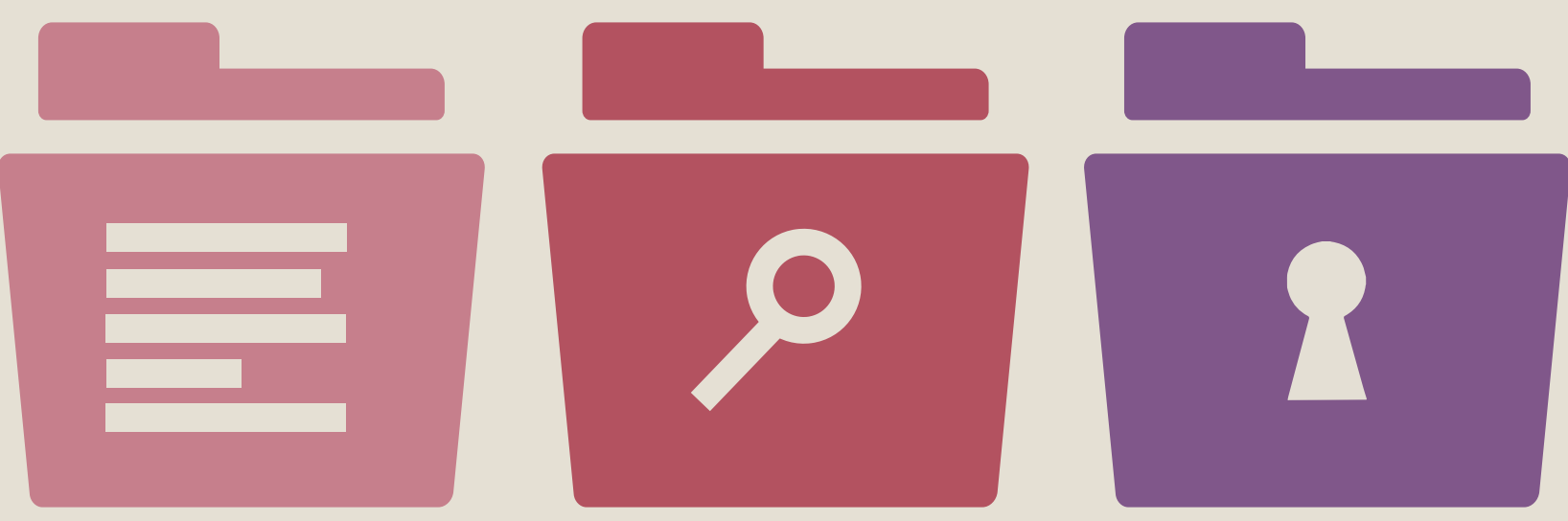

dri 


\section{Contributors from the Digital Repository of Ireland Metadata Taskforce:}

Dr. Marta Bustillo, Assistant Librarian, Metadata Cataloguer, Trinity College Dublin Damien Gallagher, Software Engineer, Maynooth University Rebecca Grant, Digital Archivist, Royal Irish Academy Dr. Natalie Harrower, Manager, Education and Outreach, Royal Irish Academy Dr. Stuart Kenny, Software Engineer, Trinity College Dublin

Dr. Agustina Martínez García, Postdoctoral Researcher, Maynooth University Dr. Rósmáire Ní Cholla, Digital Curator, National University of Ireland, Galway Dr. Aileen O'Carroll, Policy Manager, Maynooth University Sinéad Redmond, Software Engineer, Maynooth University Dr. Sharon Webb, Requirements Analyst, Maynooth University

Edited by Rebecca Grant.

First published in 2015 by the Royal Irish Academy

(C) Maynooth University, Trinity College Dublin, National University of Ireland, Galway and the Royal Irish Academy

This work is licensed under a Creative Commons Attribution 4.0 International Licence.

When citing or attributing this report please use the following: Bustillo, M., Collins, S., Gallagher, D., Grant, R., Harrower, N., Kenny, S., Martínez García, A., Ní Cholla, R., O'Carroll, A., Redmond, S. and Webb, S. (2015) Qualified Dublin Core and the Digital Repository of Ireland (R. Grant, Ed.). Maynooth: Maynooth University; Dublin: Trinity College Dublin; Dublin: Royal Irish Academy; Galway: National University of Ireland, Galway. DOI: http://dx.doi.org/10.3318/DRI.2015.3 


\section{Foreward}

The Digital Repository of Ireland (DRI) has carried out both broad and deep consultation with key institutions across Ireland to understand their metadata practices and needs. This work began in 2011 and our first findings were published in 20121. In 2013 we established a dedicated task force to consolidate our findings both nationally and internationally, and to begin a programme of guidance for best practice in metadata creation and use. This is the second in what will be an ongoing series of guidelines on metadata, suitable for various data types and disciplines within the broad domains of cultural and social data.

This document provides guidelines for preparing metadata for ingestion into the Digital Repository of Ireland, but we hope its reach will go beyond the DRI, and provide the groundwork for a cohesive and standardised approach to metadata in the Humanities and Qualitative Social Sciences in Ireland. We hope you will use these guidelines in your own institution, and encourage you to share them widely; if we adopt common or standardised metadata practices, we will have greater interoperability between our data collections, which will in turn enable improved and enhanced discovery and richer contextualised cross-collection narratives.

I cannot thank enough the experts from the broad suite of institutions who gave so generously of their time and deep expertise for this common goal. I would also like to thank the DRI team for their meticulous work on this task, which started as a simple but important concept, and grew into a complex and challenging endeavour as we embraced the diversity of data and its management practices. I hope the end result is an easy-to-use guide and reference, and we welcome your use and feedback.

Dr. Sandra Collins

Director of the Digital Repository of Ireland

Royal Irish Academy

\footnotetext{
1 Digital Archiving in Ireland: National Survey of the Humanities and Social Sciences, 2012, http://dri.ie/digital-archiving-in-ireland2012.pdf, last accessed 21 March 2014.
} 


\section{Acknowledgements}

We would like to thank the following individuals who gave so generously of their time:

Lucy Bell, Functional Director, Data Access at UK Data Archive/UK Data Service

Dr. Libby Bishop, Senior Officer, Research Data Management Support Services, UK Data Archive Martin Bradley, Archives, Digitisation, Museums and Records Management Consultant Louise Corti, Associate Director and Head ESDS Qualidata, UK Data Archive Tom Ensom, Senior Project Officer, Essex Data Repository/UK Data Service Prof. Hans Walter Gabler, Professor Emeritus, Ludwig-Maximilians-Universität, Munich Treasa Harkin, Melodies and Images Officer, Irish Traditional Music Archive Breeda Herlihy, Assistant Librarian, IR Project, University College Cork

Dr. Rene van Horik, Theme Manager, Data Archiving and Networked Services

Dr. William Kilbride, Executive Director, Digital Preservation Coalition

B. Jane Lawson, Metadata Cataloguer, Digital Resources and Imaging Services, Trinity College Dublin Kate McCarthy, DRI-INSIGHT Digital Archivist, Digital Repository of Ireland Cathal McCauley, University Librarian, Maynooth University

Dr. Elizabeth Mullins, Lecturer, School of History and Archives, University College Dublin

Hugh Murphy, Senior Librarian, Collection Management Services, Maynooth University Eoghan Ó Carragáin, Assistant Keeper II, National Library of Ireland Colum O'Riordan, Archive Administrator, Irish Architectural Archive

Catherine Ryan, Digital Librarian, Digital Repository of Ireland

Jane Stevenson, Archives Hub Manager, Archives Hub Grace Toland, Librarian, Irish Traditional Music Archive

Prof. Norman Vance, Professor of English Literature, University of Sussex 


\section{Introduction}

These guidelines are aimed at anyone using the Dublin Core metadata standard to prepare content which will be deposited with the Digital Repository of Ireland ("the Repository"). These metadata guidelines do not contradict, or indeed replace, the Dublin Core standard, but should be used in tandem with it to ensure that the metadata can be ingested and searched in the Repository.

By following these guidelines, which include mandatory and recommended elements for ingestion of metadata into the Repository, you will be making your collections more easily searchable in the Repository, and cross-searchable with other DRI collections.

\section{Mandatory and Recommended Elements}

Data must be provided for Mandatory elements to enable metadata to be ingested by the Repository; metadata will be automatically rejected by the system if Mandatory elements are not included. Recommended elements do not have to be included, but DRI strongly advises that they are completed if possible in order to facilitate searching. The remaining Qualified Dublin Core elements are Optional. All submitted elements, whether Mandatory, Recommended or Optional, will be stored and available in the Repository.

\section{What to Catalogue}

DRI recommends following the "one to one" principle of Dublin Core: the principle whereby related but conceptually different entities, for example a painting and a digital image of the painting, are described by separate metadata records. ${ }^{2}$ Metadata for a given object can refer to either the physical object or to the digital surrogate, but the information entered should not be a mixture of both.

\section{Controlled Vocabularies}

Controlled vocabularies are recommended in order to enhance the Repository's search function. Although specific controlled vocabularies are recommended in the tables below, they are not mandatory.

${ }^{2}$ http://wiki.dublincore.org/index.php/Glossary/One-to-One_Principle, last accessed 21 March 2014. 


\section{Refining Elements and MARC Relator Terms}

Qualified Dublin Core expands on the original fifteen Dublin Core elements, providing refinements to elements including Date, Relation and Format and allowing cataloguers to include more specific information about digital assets.

Qualified Dublin Core also supports the use of a subset of MARC Relator terms. These allow cataloguers to associate a specific role with the Contributor element for a digital asset, for example the role of Photographer, Printmaker, Commentator or Film Editor; and to specify that a named entity in the Subject element is depicted by the digital asset.

\section{Localised Metadata}

The Repository supports the inclusion of localised metadata by allowing the cataloguer to define the language used. This can be specified for a number of Dublin Core elements via the xml:lang attribute. The elements that support this feature are: Title, Description, Subject, Temporal Coverage, Coverage, Geographical Coverage, Source, and Rights. See "Sample DRI-compliant Qualified Dublin Core XML record" for an example of the xml:lang attribute in use.

\section{Ingesting into the Repository}

There are two methods for ingestion:

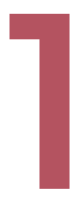

\section{Web Form Ingest}

The Repository includes a web-based user interface for single object ingest. This user interface provides blank fields to allow cataloguers to create metadata for a single digital asset. The metadata records are stored as XML and can be exported by the cataloguer as an XML file if desired.

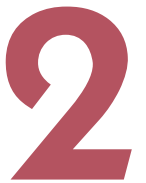

\section{XML Ingest}

Metadata in XML format can also be ingested directly into the Repository. XML metadata must be encoded using UTF-8. The appropriate namespace and schema information must be included in the header of the XML record, for example: 


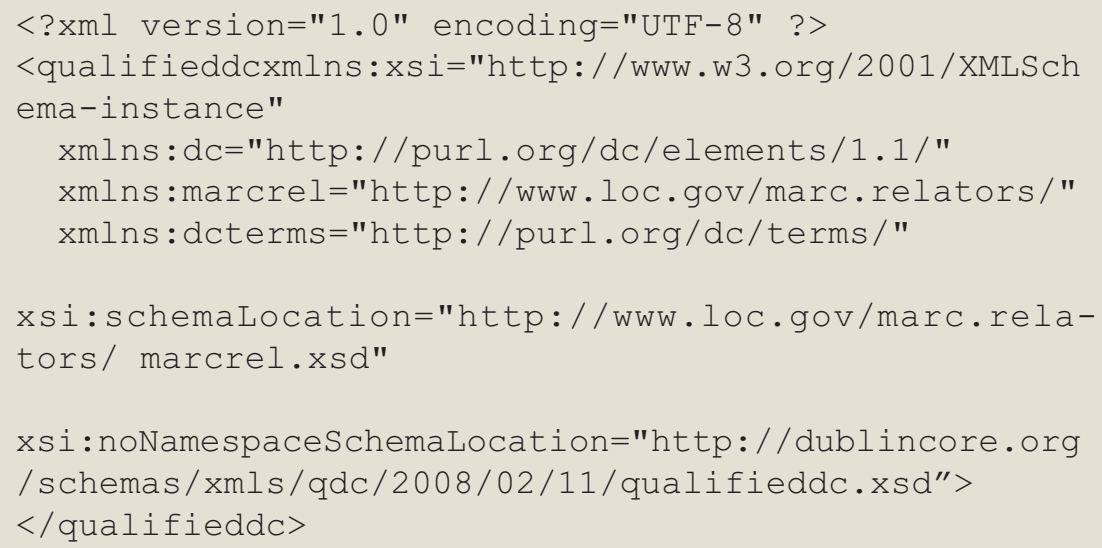

When using XML ingest, in order to match the metadata with its file, the metadata file and digital asset file should use the same filename, e.g. object1.xml and object1.tif. If there are multiple files associated with the metadata file, follow the filename with an underscore and an alphanumeric sequence, e.g. object2.xml, object2_001.tif, object2_002.tif, object2_003.tif.

\section{Please see the DRI Resources page for further information on ingestion.}

\section{Qualified Dublin Core Resources}

Guidance on using Dublin Core for Cataloguing is available here: Using Dublin Core: The Elements ${ }^{3}$ and Dublin Core User Guide. ${ }^{4}$

The Dublin Core Simple Element Set version 1.1 is currently available here: Dublin Core Metadata Element Set, Version 1.1.5

An overview of the additional Qualified Dublin Core elements and refining elements is available here: Using Dublin Core: Dublin Core Qualifiers. ${ }^{6}$

Guidance on using MARC Relators with Dublin Core is available here: MARC Relator Terms and Dublin Core. ${ }^{7}$

A list of MARC Relators which are compatible with Dublin Core is available here: Relator Terms and Dublin Core Elements. ${ }^{8}$

\footnotetext{
${ }^{3}$ http://dublincore.org/documents/usageguide/elements.shtml\#source, last accessed 14 August 2014.

${ }^{4}$ http://wiki.dublincore.org/index.php/User_Guide, last accessed 13 February 2015.

${ }^{5} \mathrm{http}: / /$ dublincore.org/documents/dces/, last accessed 14 August 2014.

${ }^{6} \mathrm{http}: / /$ dublincore.org/documents/usageguide/qualifiers.shtml, last accessed 27 November 2014.

${ }^{7}$ http://dublincore.org/usage/documents/relators/, last accessed 13 February 2015.

${ }^{8}$ http://lcweb2.loc.gov/diglib/loc.terms/relators/dc-contributor.html, last accessed 13 February 2015.
} 


\section{Table of mandatory and recommended elements, and suggested controlled vocabularies/standards for DRI}

\begin{tabular}{|c|c|c|c|c|}
\hline Element & $\begin{array}{l}\text { Refining } \\
\text { Element }\end{array}$ & Obligation & $\begin{array}{l}\text { Controlled } \\
\text { vocabulary }\end{array}$ & $\begin{array}{l}\text { Page } \\
\text { reference }\end{array}$ \\
\hline \multirow[t]{2}{*}{ Title } & & Mandatory & No & 9 \\
\hline & Alternative & Recommended & No & 16 \\
\hline \multicolumn{2}{|l|}{ Creator } & Mandatory & Yes & 9 \\
\hline \multirow[t]{3}{*}{ Date } & & $\begin{array}{l}\text { Mandatory if Issued or } \\
\text { Created are not used }\end{array}$ & Yes & 10 \\
\hline & Created & $\begin{array}{l}\text { Mandatory if Date or } \\
\text { Issued are not used }\end{array}$ & Yes & 11 \\
\hline & Issued & $\begin{array}{l}\text { Mandatory if Date or } \\
\text { Created are not used }\end{array}$ & Yes & 12 \\
\hline \multicolumn{2}{|l|}{ Description } & Mandatory & No & 13 \\
\hline Rights & & Mandatory & No & 14 \\
\hline \multicolumn{2}{|l|}{ Type } & Mandatory & Yes & 15 \\
\hline Language & & Recommended & Yes & 16 \\
\hline \multicolumn{2}{|l|}{ Contributor } & Recommended & Yes & 17 \\
\hline & MARC Relator Terms & Recommended & Yes & 17 \\
\hline \multirow[t]{9}{*}{ Relation } & & Recommended & No & 18 \\
\hline & Is Version Of & Recommended & No & 18 \\
\hline & Has Version & Recommended & No & 19 \\
\hline & Is Part Of & Recommended & No & 19 \\
\hline & Has Part & Recommended & No & 20 \\
\hline & Is Referenced By & Recommended & No & 20 \\
\hline & References & Recommended & No & 21 \\
\hline & Is Format Of & Recommended & No & 21 \\
\hline & Has Format & Recommended & No & 22 \\
\hline \multicolumn{2}{|l|}{ Source } & Recommended & No & 22 \\
\hline \multirow[t]{3}{*}{ Coverage } & & Recommended & Yes & 23 \\
\hline & Spatial & Recommended & Yes & 24 \\
\hline & Temporal & Recommended & Yes & 25 \\
\hline \multirow[t]{2}{*}{ Subject } & & Recommended & Yes & 25 \\
\hline & Depicted & Recommended & Yes & 26 \\
\hline Identifier & & Optional & No & \\
\hline \multicolumn{2}{|l|}{ Format } & Optional & No & \\
\hline Publisher & & Optional & No & \\
\hline \multicolumn{2}{|l|}{ Audience } & Optional & No & \\
\hline Provenance & & Optional & No & \\
\hline \multicolumn{2}{|l|}{ Rights Holder } & Optional & No & \\
\hline
\end{tabular}




\title{
Sample DRI-compliant Qualified Dublin Core XML record
}

\author{
$<$ ?xml version="1.0" encoding="UTF-8"?> \\ <qualifieddc xmlns:dc="http://purl.org/dc/elements/1.1/" \\ xmlns:marcrel="http://www.loc.gov/marc.relators/" \\ xmlns:dcterms="http://purl.org/dc/terms/" \\ xmlns:xsi="http://www.w3.org/2001/XMLSchema-instance" \\ xsi:schemaLocation="http://www.loc.gov/marc.relators/ marcrel.xsd" \\ xsi:noNamespaceSchemaLocation="http://dublincore.org/schemas/xmls/qdc/2008/02/11/q \\ ualifieddc.xsd"> \\ <dc:title xml:lang="ga">Muintir na nOileán</dc:title> \\ $<$ dc:creator $>$ RTÉ Raidió na Gaeltachta</dc:creator $>$ \\ <dcterms:created>Wed Apr 05 00:00:00 BST 1972</dcterms:created> \\ <dc:description xml:lang="ga">Seo an chéad chlár as péire a taifeadadh istigh in \\ Inis Bearachain Co. na Gaillimhe ina bhfuil stiofán ó Cualáin as Carna ag cur síos \\ ar a chuid laethanta múinteoireachta san oileán. Labhraíonn sé ar na Seoighe agus \\ An Tóstal agus deir sé focail an amhráin faoin Seoighe Inis Bearachain a chum Val \\ Bheartla Uí Dhonnchú. Seinntear an t-amhrán Inis Barr an Chuain. \\ $</$ dc: description> \\ <dc: description $\mathrm{xml}$ : lang="en">This is the first of two programmes recorded in \\ Inishbarra, Co. Galway, in which Stiofán Ó Cualáin from Carna describes the time \\ he spent teaching on the island. He speaks about the Joyces and recites the words \\ of the song about the Joyces of Inishbarra composed by Val Bheartla Uí Dhonnchú. \\ The programme also features the song Inis Barr an Chuain.</dc:description>
}

<dc:rights xml:lang="ga">RTÉ Raidió na Gaeltachta</dc:rights>

$<$ dc: type $>$ Sound $</$ dc: type $>$

<dcterms:extent>Sun Dec 31 00:20:00 GMT 1899</dcterms:extent>

$<$ dc: language $>$ ga $</$ dc: language $>$

$<$ marcrel:cmm>ó Cualáin, Stiofán</marcrel:cmm>

$<$ marcrel:cmm>ó Conaola, Maidhc P.</marcrel:cmm>

<marcrel:cmm>Seoighe, Cóilín</marcrel:cmm>

<marcrel:cmm>Choilmín' Seoighe, Máirtín 'Chóilín</marcrel:cmm>

$<$ marcrel:cmm>ó Conaola, Maidhc P.</marcrel:cmm>

$<$ marcrel:pro>ó Conaola, Maidhc P.; $<$ /marcrel:pro $>$

$<$ marcrel:hst>ó Conaola, Maidhc P.; $<$ /marcrel:hst $>$

$<$ marcrel:cmm>Seoighe, Cóilín</marcrel:cmm>

<dc:source xml:lang="ga">Cartlann RTÉ Raidió na Gaeltachta</dc:source>

<dcterms:spatial xml:lang="ga">Co. na Gaillimhe</dcterms:spatial>

<dcterms:spatial xml:lang="en">Inishbarra</dcterms:spatial>

<dcterms:spatial xml:lang="en">Co. Galway</dcterms:spatial>

<dcterms:spatial xml:lang="ga">Inis Bearachain</dcterms:spatial>

<dc:subject xml:lang="ga">Pobail oileán</dc:subject>

$<$ dc:subject xml:lang="ga">Beathaisnéis $</$ dc:subject $>$

$<$ dc:subject xml:lang="ga">Inis Bearachain</dc:subject $>$

$<$ dc: subject xml:lang="ga">Co. na Gaillimhe</dc:subject $>$

$<$ dc: subject $\mathrm{xml}$ :lang="ga">Stair</dc:subject $>$

<dc:subject xml:lang="ga">Stair áitiúil</dc:subject>

$<$ dc:subject xml:lang="ga">Gaeltachtaí/dc:subject>

$<$ dc: subject xml:lang="ga">Ceol traidisiúnta</dc:subject $>$

$<$ dc:subject xml:lang="en">Island communities</dc:subject>

$<$ dc: subject xml:lang="en">Biography</dc:subject>

<dc:subject xml:lang="ga">Inis Bearacháín</dc:subject>

$<$ dc:subject xml:lang="en">Co. Galway</dc:subject $>$

$<$ dc: subject $\mathrm{xml}$ :lang="en" $>$ History $</$ dc: subject $>$

$<$ dc: subject $\mathrm{xml}$ :lang="en">Local history</dc:subject $>$

<dc:subject xml:lang="en">Gaeltacht areas Irish traditional music</dc:subject> <dc:identifier>67879-CD2237-Nuig2237_06.mp3</dc:identifier>

<dc:publisher>RTÉ Raidió na Gaeltachta</dc:publisher>

$</$ qualifieddc $>$ 


\section{Key to the Tables:}

Label

This is the name of the metadata element taken from the Dublin

Core documentation, for example "Title".

Metadata Element

This is the Dublin Core XML encoding of the metadata element, for example dc:title

The metadata elements described in these guidelines use the

following namespace prefixes:

dc: for Dublin Core elements

dcterms: for Qualified Dublin core elements

marcrel: for MARC Relator Terms.

Definition

This is the formal definition of the element, taken from the Dublin Core documentation.

Format of content

This is the type of data entered in the metadata element, for example free text, or a suggested controlled vocabulary.

Obligation

This field details whether or not the element is a required field for ingest into the Repository. Elements are designated as either Mandatory or Recommended. Optional elements are not detailed in this document as they do not have DRI-specific recommendations associated with them.

Repeatable

This field details whether or not the metadata standard allows more than one use of the metadata element. For example, if it is possible to enter more than one Subject the element is repeatable, e.g.

$<$ dc : subject $>$ Cow $</$ dc $:$ subject $>$

$<$ dc: subject $>$ Mammal $</$ dc : subject $>$

All Dublin Core elements are repeatable.

Values (examples)

This field gives example instances of the types of values that might be entered in the element. 


\section{Mandatory Elements}

\begin{tabular}{|c|c|}
\hline Label & Title $^{9}$ \\
\hline Metadata Element & $<$ dc:title $>$ \\
\hline Definition & $\begin{array}{l}\text { A name given to the resource. Typically, a Title will be a name by which the } \\
\text { resource is formally known. }\end{array}$ \\
\hline Format of content & Free text \\
\hline Obligation & Mandatory \\
\hline Repeatable & Yes \\
\hline \multirow[t]{4}{*}{ Values (examples) } & $<$ dc:title $>$ Ulysses $</$ dc:title $>$ \\
\hline & <dc:title>Childhood in Ireland: A Qualitative \\
\hline & Study</dc:title $>$ \\
\hline & <dc:title $>$ The Morning Show</dc:title $>$ \\
\hline
\end{tabular}

\section{Label \\ Metadata Element \\ Definition}

Creator ${ }^{10}$

$<$ dc:creator $>$

An entity primarily responsible for making the content of the resource.

Examples of a Creator include a person, an organization, or a service. Typically the name of the Creator should be used to indicate the entity.

Format of content Personal, family and corporate names should preferably be formatted according to the Irish Guidelines for Indexing Archives. ${ }^{11}$

\section{Obligation Mandatory}

Repeatable Yes

Values (examples) <dc:creator>Irish Qualitative Data Archive, Maynooth University</dc:creator $>$

<dc:creator>Radio na Gaeltachta, 1972-</dc:creator >

<dc:creator>Joyce, James, 1882-1941</dc:creator >

Notes

For Irish family names, such as Mary Choilm a' tSeaimpín, where Choilm a' tSeaimpín is a family identifier rather than a surname and cannot precede Mary, DRI suggests that the family identifier should follow the first name. If the creator is unknown, some term should be entered in the Creator element to signal this, such as "Unknown" or "Anonymous". However, if the cataloguer would prefer to leave the element blank, they should fill in "null".

\footnotetext{
${ }^{9} \mathrm{http} / / /$ purl.org/dc/elements/1.1/title, last accessed 14 August 2014.

${ }^{10} \mathrm{http}: / /$ purl.org/dc/elements/1.1/creator, last accessed 14 August 2014.

${ }^{11} \mathrm{http}: / /$ www.learnaboutarchives.ie/ learnabo/images/documents/ARAlndexing.pdf, last accessed 14 August 2014
} 


\section{Mandatory Elements}

Label

Metadata Element

Definition

Format of content

\section{Obligation \\ Repeatable \\ Values (examples) \\ Notes}

\section{Date $^{12}$}

$<$ dc $:$ date $>$

A point or period of time associated with an event in the lifecycle of the resource.

Date should preferably be formatted according to the W3C Note on Date and Time Formats ${ }^{13}$, ISO $8601^{14}$ or the DCMI Period Encoding Scheme. ${ }^{15}$ Although dates which are not formatted in this way can be included, they will not be indexed and fully searchable in the Repository.

Mandatory if Created or Issued are not used

Yes

<dc:date>2013-11-05</dc:date>

Date may refer to published date, broadcast date, object creation date, etc. Dates can be identified more specifically by using Qualified Dublin Core Refining elements.

If the date is unknown and the cataloguer would prefer to leave the element blank rather than write "Unknown," they should fill in "null".

The Repository supports the inclusion of date spans encoded as DCMI Period, and will also index uncertain dates which are prefaced by "circa" or "ca" if the desired date range is encoded appropriately.

If the desired display date is "circa 1935" then it could for example be encoded with a ten year span (1930-1940) and would then be searchable by any date within this span. Although the span is indexed for search, the display date defined as name= will be the only part of the date which is displayed by the Repository.

The encoding scheme used (either W3C-DTF or ISO 8601) must be included. For example:

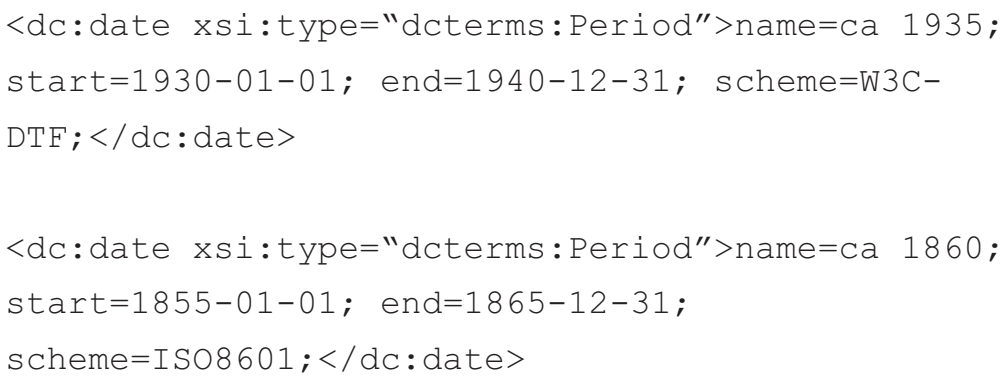




\section{Mandatory Elements}

\section{Element refinement for $\langle$ dc : date $>$}
Label
Metadata Element
Definition
Format of content

\section{Obligation \\ Repeatable \\ Values (examples)}

Notes

\section{Created ${ }^{16}$}

$<$ dcterms:created $>$

Date of creation of the resource.

Date should preferably be formatted according to the W3C Note on Date and Time Formats ${ }^{17}$, ISO $8601^{18}$ or the DCMI Period Encoding Scheme. ${ }^{19}$ Although dates which are not formatted in this way can be included, they will not be indexed and fully searchable in the Repository.

Mandatory if Date or Issued are not used.

Yes

<dcterms: created>2013-11-05</dcterms : created>

<dcterms: created>start=1960-01-01; end=1969-01-

$31 ;</$ dcterms : created>

If the date is unknown and the cataloguer would prefer to leave the element blank rather than write "Unknown," they should fill in "null".

The Repository supports the inclusion of date spans encoded as DCMI Period, and will also index uncertain dates which are prefaced by "circa" or "ca" if the desired date range is encoded appropriately.

If the desired display date is "circa 1935" then it could for example be encoded with a ten year span (1930-1940) and would then be searchable by any date within this span. Although the span is indexed for search, the display date defined as name $=$ will be the only part of the date which is displayed by the Repository.

The encoding scheme used (either W3C-DTF or ISO 8601) must be included.

For example:

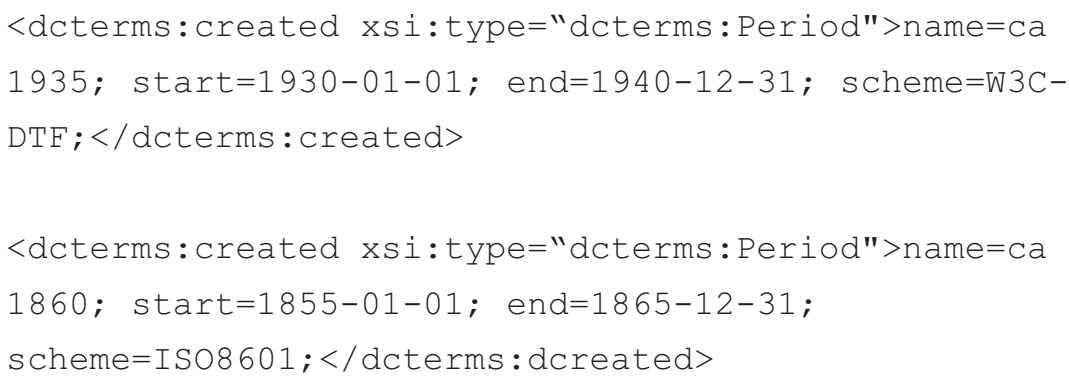

${ }^{16} \mathrm{http}: / /$ dublincore.org/documents/dcmi-terms/\#terms-created, last accessed 27 February 2015.

$17 \mathrm{http}: / / \mathrm{www} . w 3.0 \mathrm{rg} / \mathrm{TR} / \mathrm{NOTE}-$ datetime, last accessed 14 August 2014.

$18 \mathrm{http}: / / \mathrm{www}$.iso.org/iso/home/standards/iso8601.htm, last accessed 14 August 2014.

$19 \mathrm{http}: / /$ dublincore.org/documents/dcmi-period/, last accessed 14 August 2014. 


\section{Mandatory Elements}

\section{Element refinement for $\langle$ dc: date $>$}

Label

Metadata Element

Definition

Format of content

Obligation

Repeatable

Values (examples)

Notes
Issued ${ }^{20}$

$<$ dcterms: issued $>$

Date of formal issuance (e.g. publication) of the resource.

Date should preferably be formatted according to the W3C Note on Date and Time Formats ${ }^{21}$, ISO $8601^{22}$ or the DCMI Period Encoding Scheme. ${ }^{23}$ Although dates which are not formatted in this way can be included, they will not be indexed and fully searchable in the Repository.

Mandatory if Date or Created are not used Yes

<dcterms: issued>2013-11-05</dcterms: issued>

<dcterms: issued $>1995</$ dcterms: issued $>$

If the date is unknown and the cataloguer would prefer to leave the element blank rather than write "Unknown," they should fill in "null".

The Repository supports the inclusion of date spans encoded as DCMI Period, and will also index uncertain dates which are prefaced by "circa" or "ca" if the desired date range is encoded appropriately.

If the desired display date is "circa 1935" then it could for example be encoded with a ten year span (1930-1940) and would then be searchable by any date within this span. Although the span is indexed for search, the display date defined as name $=$ will be the only part of the date which is dis played by the Repository.

The encoding scheme used (either W3C-DTF or ISO 8601) must be included.

For example:

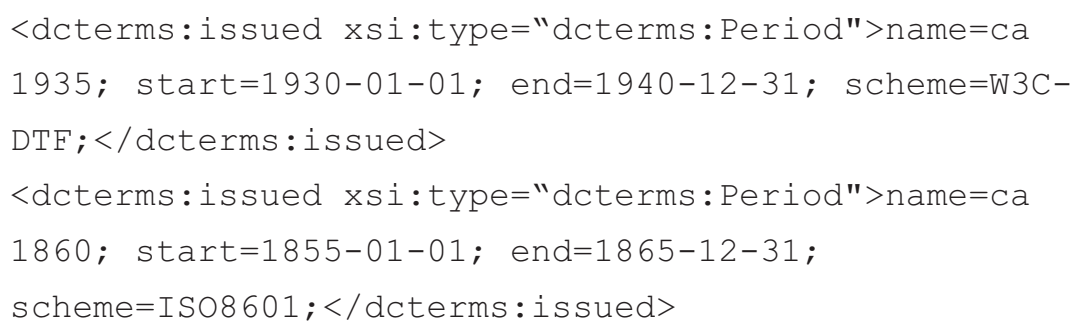

20 http://dublincore.org/documents/dcmi-terms/\#terms-issued, last accessed 27 February 2015.

21 http://www.w3.org/TR/NOTE-datetime, last accessed 14 August 2014.

$22 \mathrm{http}: / / \mathrm{www}$.iso.org/iso/home/standards/iso8601.htm, last accessed 14 August 2014.

${ }^{23} \mathrm{http}: / /$ dublincore.org/documents/dcmi-period/, last accessed 14 August 2014. 


\section{Mandatory Elements}

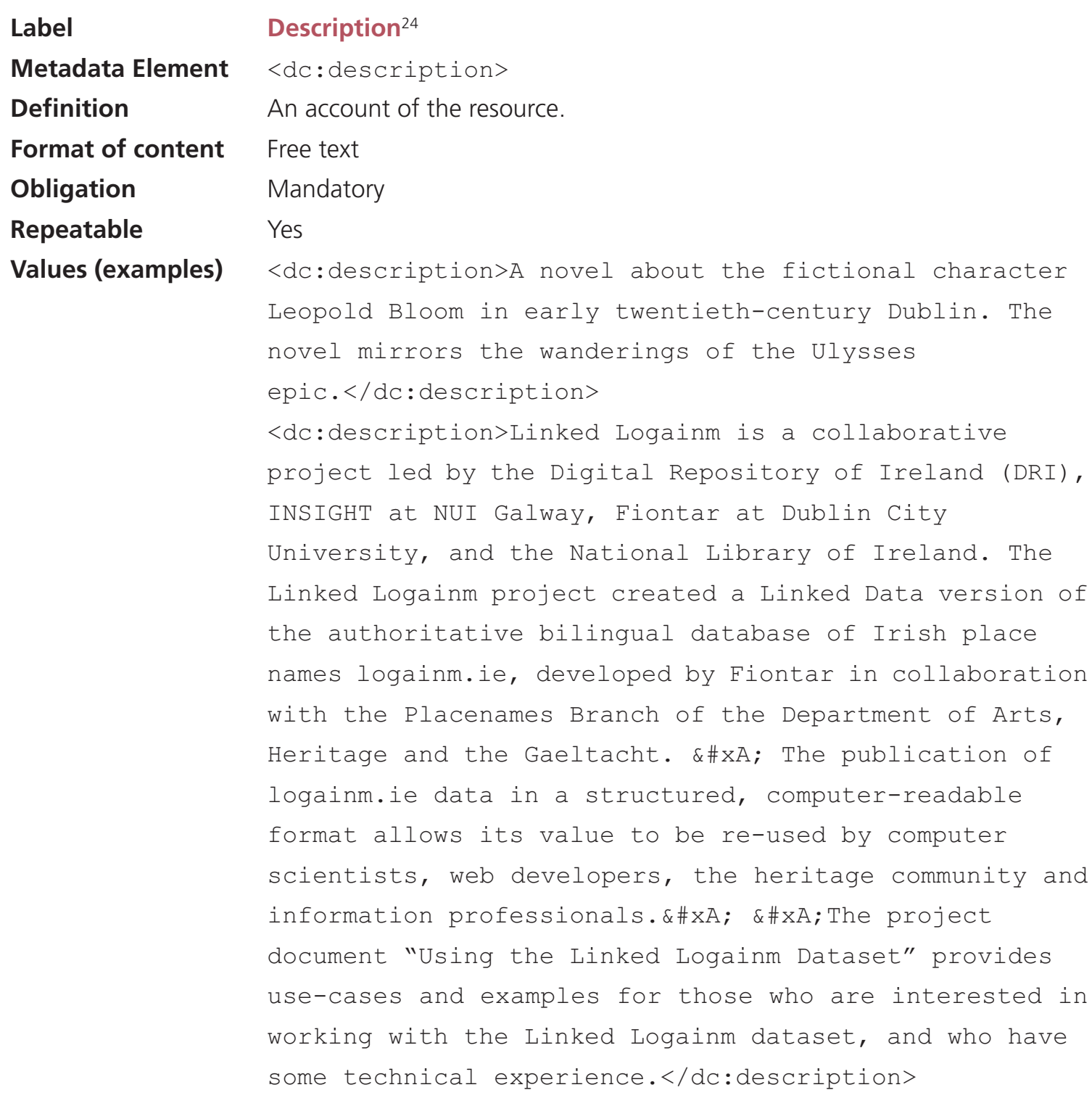

\section{Description $^{24}$}

$<d c$ :description>

An account of the resource.

Free text

Mandatory

Yes

$<$ dc:description $>$ A novel about the fictional character Leopold Bloom in early twentieth-century Dublin. The novel mirrors the wanderings of the Ulysses epic.</dc:description>

$<$ dc:description>Linked Logainm is a collaborative project led by the Digital Repository of Ireland (DRI), INSIGHT at NUI Galway, Fiontar at Dublin City University, and the National Library of Ireland. The Linked Logainm project created a Linked Data version of the authoritative bilingual database of Irish place names logainm.ie, developed by Fiontar in collaboration with the Placenames Branch of the Department of Arts, Heritage and the Gaeltacht. \&\#xA; The publication of logainm.ie data in a structured, computer-readable format allows its value to be re-used by computer scientists, web developers, the heritage community and information professionals.\&\#xA; \&\#xA; The project document "Using the Linked Logainm Dataset" provides use-cases and examples for those who are interested in working with the Linked Logainm dataset, and who have some technical experience. $</$ dc:description $>$

Notes
Description may include but is not limited to: an abstract, a table of contents, or a free-text account of the resource.

For long descriptions, the Repository supports the inclusion of paragraphs and line breaks.

When using the ingest form, pressing return will create a line break which will be displayed in the Repository's user interface. Pressing return twice will create a new paragraph.

When creating XML metadata, \&\#xD; may be used to create a carriage return, while \&\#xA; will create a line break. The inclusion of two carriage returns or line breaks consecutively, for example \&\#xA;\&\#xA; will create a paragraph break. 
Mandatory Elements

Label
Metadata Element
Definition
Format of content
Obligation
Repeatable
Values (examples)

Notes
Rights $^{25}$

$<$ dc:rights $>$

Information about rights held in and over the resource. Typically a Rights element will contain a rights management statement for the resource, or reference a service providing such information. Rights information often encompasses Intellectual Property Rights (IPR), Copyright, and various Property Rights.

Free text

Mandatory

Yes

$<$ dc:rights>Copyright National Library of Ireland, $2013</$ dc:rights $>$

<dc:rights>Copyright IQDA, Maynooth University. All

rights reserved</dc:rights $>$

<dc:rights>Copyright Radio na Gaeltachta. This work is

licensed under a Creative Commons Attribution-NoDerivs

3.0 Ireland Licence. Please use the following

attribution when citing this work: Copyright Radio na

Gaeltachta, digital surrogate created by the DRI NUI

Galway Demonstrator Project</dc:rights $>$

This element may include both rights information, and information on how the resource can be reused.

${ }^{25} \mathrm{http} / / /$ purl.org/dc/elements/1.1/rights, last accessed 14 August 2014. 
Mandatory Elements

\begin{tabular}{|c|c|}
\hline Label & Type 26 \\
\hline Metadata Element & $<$ dc: type $>$ \\
\hline Definition & $\begin{array}{l}\text { The nature or genre of the content of the r } \\
\text { describing general categories, functions, ge } \\
\text { content. }\end{array}$ \\
\hline \multirow[t]{5}{*}{ Format of content } & Free text \\
\hline & Recommended controlled vocabulary for th \\
\hline & DCMI Type Vocabulary. ${ }^{27}$ \\
\hline & Other recommended vocabularies are availa \\
\hline & page. ${ }^{28}$ \\
\hline Obligation & Mandatory \\
\hline Repeatable & Yes \\
\hline \multirow[t]{5}{*}{ Values (examples) } & <dc:type>Dataset</dc:type $>$ \\
\hline & $<$ dc: type $>$ Moving Image $</$ dc: type $>$ \\
\hline & $<$ dc: type $>$ Text $</$ dc $:$ type $>$ \\
\hline & $<$ dc: type $>$ Newspapers</dc:type $>$ \\
\hline & <dc:type $>$ Periodicals</dc:type $>$ \\
\hline
\end{tabular}

\footnotetext{
$26 \mathrm{http}: / /$ purl.org/dc/elements/1.1/type, last accessed 14 August 2014

27 http://dublincore.org/documents/2000/07/11/dcmi-type-vocabulary/, last accessed 14 August 2014.

${ }^{28} \mathrm{http}: / /$ dri.ie/vocabularies, last accessed 21 October 2014.
} 


\section{Recommended Elements}

\section{Element refinement for $\langle$ dc: title $>$}

\section{Label}

Metadata Element

Definition

Format of content

Obligation

Repeatable

Values (examples)
Alternative ${ }^{29}$

<dcterms:alternative>

An alternative name for the resource. The distinction between titles and alternative titles is application-specific.

Free text

Recommended

Yes

<dc:title xml:lang="ga">Muintir na noileán</dc:title>

$<$ dc:title $>$ The Three Musketeers</dc:title>

<dcterms:alternative>Les Trois

Mousquetaires</dcterms:alternative>

\section{Label \\ Language ${ }^{30}$}

Metadata Element

Definition

Format of Content

Obligation

Repeatable

Values (examples) RFC5646.32

Yes
$<$ dc: language $>$

A language of the resource.

Languages should preferably be formatted according to ISO63931 or

Recommended

$<$ dc: language $>$ en $</$ dc: language $>$

$<\mathrm{dc}$ : language $>$ eng $<\mathrm{dc}:$ language $>$

$<$ dc: language $>$ ga $</$ dc: language $>$

$<$ dc: language $>$ gle $<$ dc: language $>$

${ }^{29} \mathrm{http}: / /$ dublincore.org/documents/2012/06/14/dcmi-terms/?v=terms\#alternative, last accessed 27 February 2015.

${ }^{30} \mathrm{http}: / /$ purl.org/dc/elements/1.1/language, last accessed 14 August 2014.

${ }^{31} \mathrm{http}: / /$ www.loc.gov/standards/iso639-2/php/code_list.php, last accessed 14 August 2014.

32 http://tools.ietf.org/html/rfc5646, last accessed 14 August 2014. 


\section{Recommended Elements}

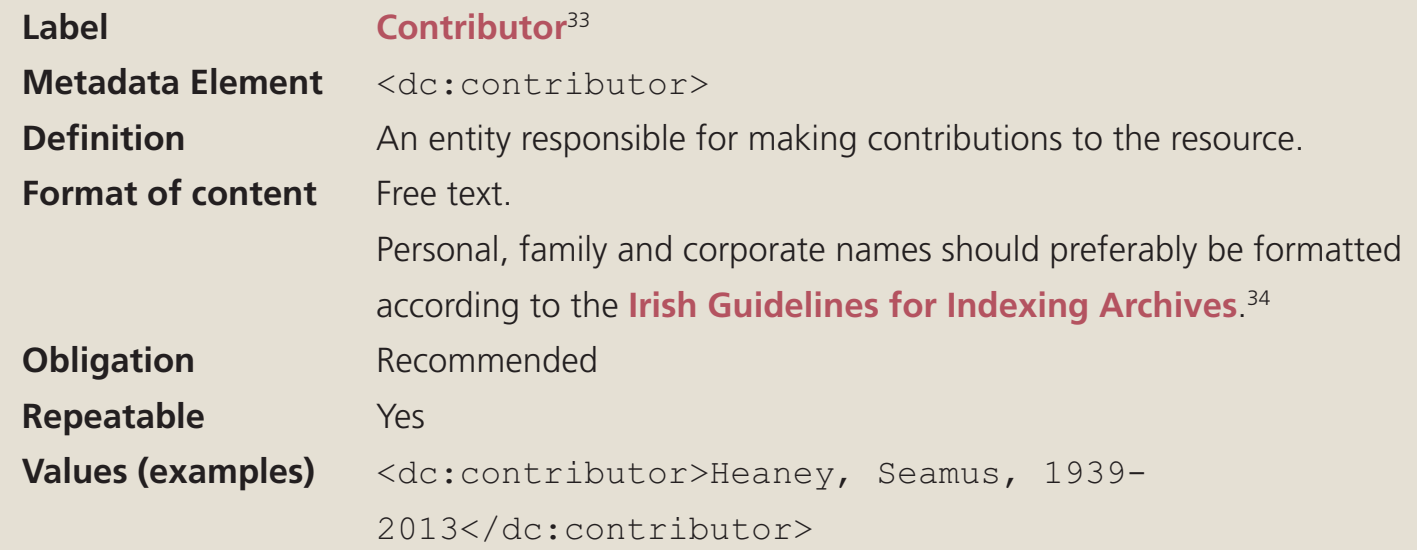

\section{Element refinement for <dc: contributor $>$}

\section{Label}

Metadata Element

Definition

Format of content

Obligation

Repeatable

Values (examples)
Dublin Core MARC Relator Terms ${ }^{35}$

<marcrel:MARC relator code indicating a refinement> An entity responsible for making contributions to the resource.

Dublin Core MARC Relator terms may be used to describe the relationship of the named Contributor to the digital object.

A list of MARC Relator terms which are compatible with Dublin Core is available here: Relator Terms and Dublin Core Elements. ${ }^{36}$

Free text.

Personal, family and corporate names should preferably be formatted according to the Irish Guidelines for Indexing Archives. ${ }^{37}$

Recommended

Yes

<marcrel:aut>Joyce, James, 1882-1941</marcrel:aut>

<marcrel:cmm>Báille, Micil</marcrel:cmm>

${ }^{33} \mathrm{http} / / /$ purl.org/dc/elements/1.1/contributor, last accessed 14 August 2014.

${ }^{34} \mathrm{http}: / /$ www.learnaboutarchives.ie/ learnabo/images/documents/ARAlndexing.pdf, last accessed 14 August 2014.

35 http://lcweb2.loc.gov/diglib/loc.terms/relators/dc-contributor.html, last accessed 14 August 2014.

${ }^{36} \mathrm{http}: / / / \mathrm{lcweb2}$.loc.gov/diglib/loc.terms/relators/dc-contributor.html, last accessed 13 February 2015.

$37 \mathrm{http}: / / \mathrm{www}$.learnaboutarchives.ie/ learnabo/images/documents/ARAlndexing.pdf, last accessed 14 August 2014. 


\section{Recommended Elements}

\begin{tabular}{|c|c|}
\hline Label & Relation ${ }^{38}$ \\
\hline Metadata Element & <dc:relation> \\
\hline Definition & $\begin{array}{l}\text { A reference to a related resource. Recommended best practice is to reference } \\
\text { the resource by means of a string or number conforming to a formal } \\
\text { identification system. }\end{array}$ \\
\hline Format of content & Free text \\
\hline Obligation & Recommended \\
\hline Repeatable & Yes \\
\hline Values (example) & $\begin{array}{l}<\text { dc:relation }>\text { DOI: } 10.3318 / D R I .2013 .1</ \text { dc:relation }> \\
<d c: \text { relation }>\text { This text is a translation of } \\
\text { DOI: } 10.3318 / D R I . \text { LODer.2013.3</dc:relation }>\end{array}$ \\
\hline Notes & $\begin{array}{l}\text { DOls, URLs, and library codes or references to demonstrate a relationship } \\
\text { between objects may be included in this element. }\end{array}$ \\
\hline
\end{tabular}

\section{Element refinement for $\langle$ dc: relation $>$}

\section{Label \\ Metadata Element \\ Definition}

Format of content

Obligation

Repeatable

Values (examples)

\section{Is Version Of ${ }^{39}$}

<dcterms: isVersionof>

The described resource is a version, edition, or adaptation of the referenced resource. Changes in version imply substantive changes in content rather than differences in format.

Free text

Recommended

Yes

West Side Story may have:

<dcterms:isversionof>Romeo and Juliet

$</$ dcterms:isversionof $>$

DOIs, URLs, and library codes or references to demonstrate a relationship between objects may be included in this element.

\footnotetext{
$38 \mathrm{http}: / /$ purl.org/dc/elements/1.1/relation, last accessed 14 August 2014.

$39 \mathrm{http}: / /$ dublincore.org/documents/2012/06/14/dcmi-terms/?v=terms\#terms-isVersionOf, last accessed 27

February 2015
} 


\section{Recommended Elements}

\section{Element refinement for $\leq$ dc : relation $>$}

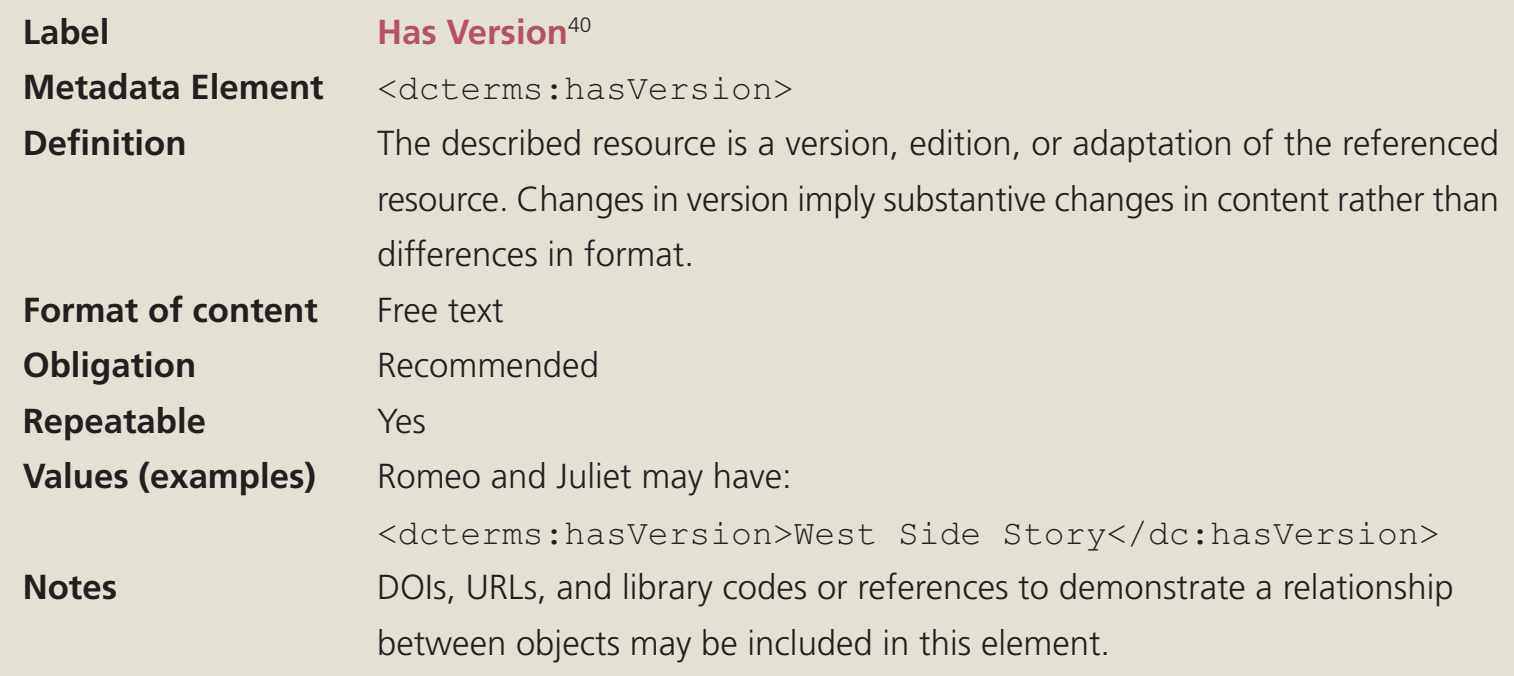

\section{Element refinement for $\langle$ dc : relation $>$}

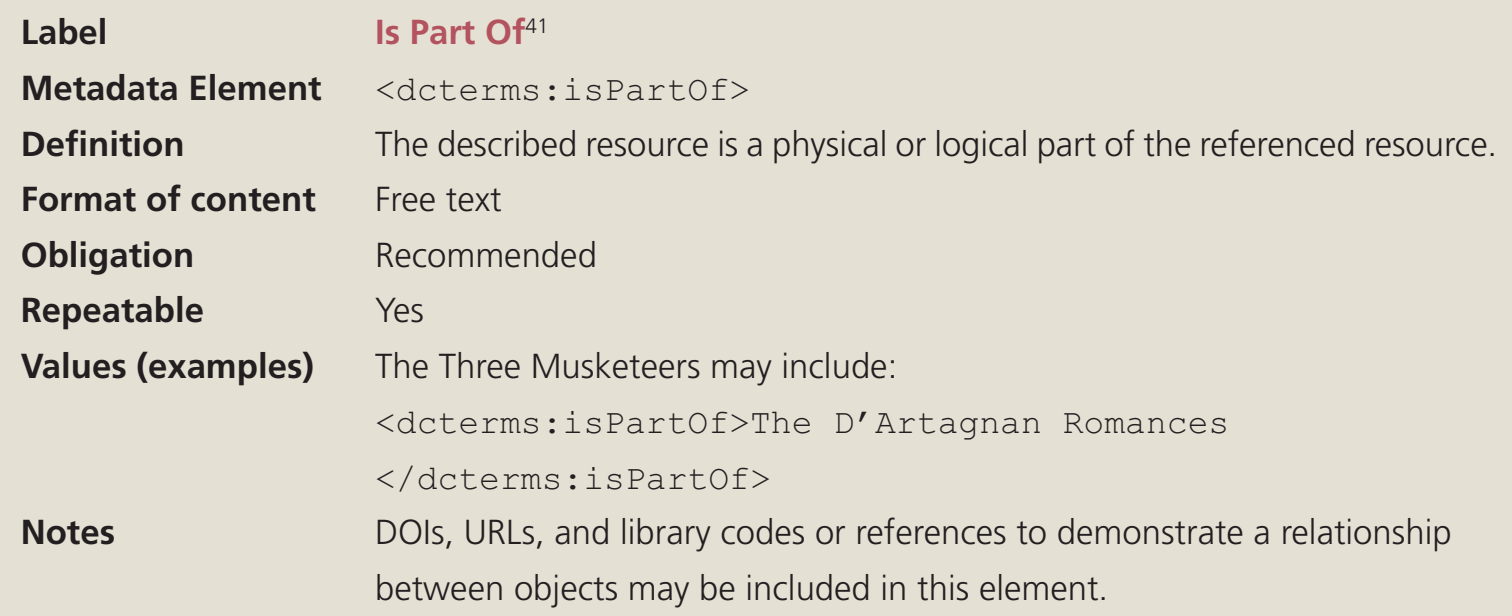
between objects may be included in this element.

40 http://dublincore.org/documents/2012/06/14/dcmi-terms/?v=terms\#terms-hasVersion, last accessed 27 February 2015.

${ }^{41} \mathrm{http} / / /$ dublincore.org/documents/2012/06/14/dcmi-terms/?v=terms\#terms-isPartOf, last accessed 27 February 2015. 


\section{Recommended Elements}

\section{Element refinement for $\langle$ dc : relation>}

\author{
Label \\ Metadata Element \\ Definition
}

Format of content

Repeatable

Values (examples)
Obligation

Has Part ${ }^{42}$

<dcterms: hasPart>

The described resource includes the referenced resource either physically or logically.

Free text

Recommended

Yes

A record for the D'Artagnan Romances may include:

<dcterms:hasPart>The Three Musketeers</dc:hasPart> $<$ dcterms:hasPart $>$ Twenty Years After $</$ dc:hasPart $>$ <dcterms:hasPart>The Vicomte de Bragelonne</dc:hasPart> <dcterms:hasPart>Louise de la Vallière</dc:hasPart> <dcterms:hasPart>The Man in the Iron Mask</dc:hasPart>

Notes DOls, URLs, and library codes or references to demonstrate a relationship between objects may be included in this element.

\section{Element refinement for $\langle$ dc : relation $>$}
Label
Is Referenced By ${ }^{43}$

Metadata Element

<dcterms:isReferencedBy>

Definition

The described resource is referenced, cited, or otherwise pointed to by the referenced resource.

Format of content Free text

\section{Obligation}

Recommended

Repeatable Yes

Values

<dcterms:isReferencedBy>DOI : 10.3318/DRI.2015.1

$</$ dcterms:isReferencedBy $>$

<dcterms:isReferencedBy>This essay is cited in Art and

Architecture of Ireland Volume V: Twentieth

century</dcterms: isReferencedBy>

Notes

DOls, URLs, and library codes or references to demonstrate a relationship between objects may be included in this element.

42 http://dublincore.org/documents/2012/06/14/dcmi-terms/?v=terms\#terms-hasPart, last accessed 27 February 2015.

${ }^{43} \mathrm{http} / / /$ dublincore.org/documents/2012/06/14/dcmi-terms/?v=terms\#terms-isReferencedBy, last accessed 27 February 2015. 


\section{Recommended Elements}

\section{Element refinement for <dc: relation>}

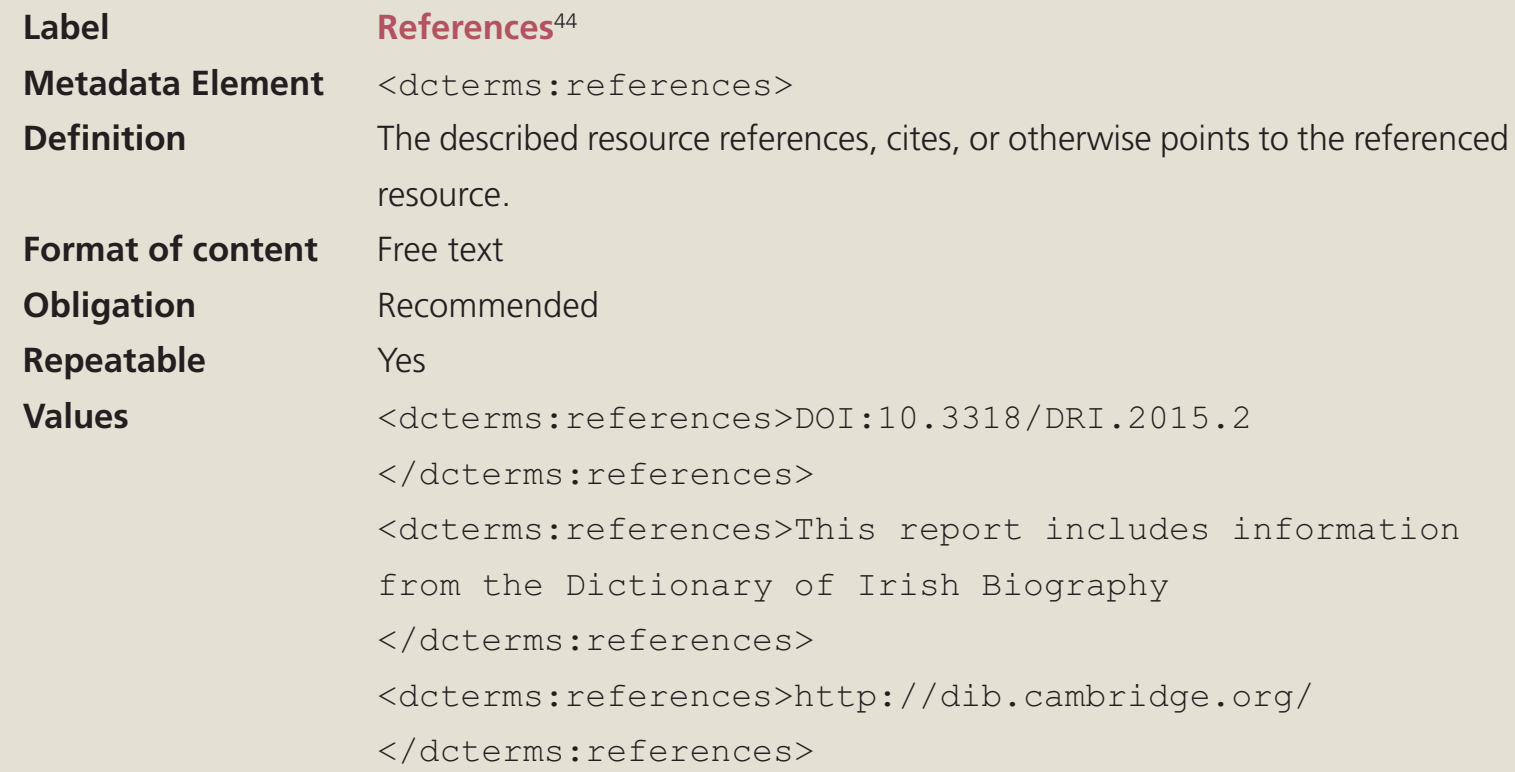

Notes

DOIs, URLs, and library codes or references to demonstrate a relationship between objects may be included in this element.

\section{Element refinement for <dc: relation>}

\section{Label Is Format Of 45}

Metadata Element <dcterms:isFormatof>

Definition A related resource that is substantially the same as the described resource, but in another format.

Format of content Free text

Obligation Recommended

Repeatable Yes

Values (examples) For a text transcription of a PDF image:

<dcterms: isFormatof >NULU01image</dcterms: isFormatof $>$

Notes DOIs, URLs, and library codes or references to demonstrate a relationship between objects may be included in this element.

${ }^{44} \mathrm{http}: / /$ dublincore.org/documents/2012/06/14/dcmi-terms/?v=terms\#terms-references, last accessed 27 February 2015

${ }^{45} \mathrm{http} / / /$ dublincore.org/documents/2012/06/14/dcmi-terms/?v=terms\#terms-isFormatOf, last accessed 27 February 2015. 


\section{Recommended Elements}

\section{Element refinement for $\langle\mathrm{dc}:$ relation $>$}

Label

Metadata Element

Definition

Format of content

Obligation

Repeatable

Values (examples)

Notes

\section{Has Format ${ }^{46}$}

<dcterms: hasFormat>

A related resource that is substantially the same as the pre-existing described resource, but in another format.

Free text

Recommended

Yes

<dcterms:hasFormat>This audio file is also available as a text transcription, NULU01text.</dcterms:hasFormat> DOls, URLs, and library codes or references to demonstrate a relationship between objects may be included in this element.

\section{Label}

\section{Source ${ }^{47}$}

Metadata Element

Definition

$<\mathrm{dc}$ : source>

Format of content Free text

Obligation

Recommended

Repeatable

Yes

Values (examples)

<dc:source>This image is taken from Folio $202 \mathrm{~V}$ of the Book of Kells</dc:source $>$

<dc:source> Transcript from audio John Kelly inter view $</$ dc: source $>$

Notes DOIs, URLs, and library codes or references to demonstrate a relationship between objects may be included in this element.

${ }^{46} \mathrm{http}: / /$ dublincore.org/documents/2012/06/14/dcmi-terms/?v=terms\#terms-hasFormat, last accessed 27 February 2015.

${ }^{47} \mathrm{http}: / /$ purl.org/dc/elements/1.1/source, last accessed 14 August 2014. 


\section{Recommended Elements}

\section{Label \\ Metadata Element \\ Definition}

Format of content

\section{Obligation}

Repeatable

Values (examples)

\section{Coverage ${ }^{48}$}

$<$ dc: coverage >

The spatial or temporal topic of the resource, the spatial applicability of the resource, or the jurisdiction under which the resource is relevant.

Free text.

Geo-codes should preferably be formatted according to the DCMI Point Encoding Scheme ${ }^{49}$, and the DCMI Box Encoding Scheme. ${ }^{50}$ Temporal data should preferably be formatted according to the DCMI Period Encoding Scheme ${ }^{51}$, W3C Note on Date and Time Formats ${ }^{52}$ or ISO $8601^{53}$; or the Library of Congress Subject Headings for named periods ${ }^{54}$.

Recommended

Yes

<dc: coverage>1918-11-11</dc: coverage>

<dc:coverage xsi:type="dcterms:Period" $>$ name=The 1960s;

start=1960-01-01; end=1969-12-31; <dc: coverage>

$<$ dc:coverage $>$ Early Modern History $</$ dc:coverage $>$

$<$ dc: coverage $>$ Spain</dc: coverage</dc: coverage $>$

$<$ dc: coverage $>$ name=Western Australia; northlimit $=-13.5$; southlimit $=-35.5$;

westlimit $=112.5$; eastlimit $=129</$ dc : coverage $>$

<dc: coverage>http://data.logainm.ie/place/49237</dc: co

verage>

<dc: coverage>http://sws.geonames.org/3301443/</dc:co

verage>

<dc: coverage>http://id.worldcat.org/fast/1271105</

dc: coverage>

\footnotetext{
${ }^{48} \mathrm{http}: / /$ purl.org/dc/elements/1.1/coverage, last accessed 14 August 2014.

${ }^{49} \mathrm{http}: / /$ dublincore.org/documents/dcmi-point/, last accessed 14 August 2014.

$50 \mathrm{http} / / /$ dublincore.org/documents/dcmi-box/, last accessed 14 August 2014.

${ }^{51} \mathrm{http}: / /$ dublincore.org/documents/dcmi-period/, last accessed 14 August 2014.

$52 \mathrm{http}: / /$ www.w3.org/TR/NOTE-datetime, last accessed 14 August 2014.

$53 \mathrm{http}: / / \mathrm{www}$.iso.org/iso/home/standards/iso8601.htm, last accessed 14 August 2014.

${ }^{54}$ http://id.loc.gov/authorities/subjects.html, last accessed 21 March 2014.
} 


\section{Recommended Elements}

\section{Element refinement for <dc: coverage>}

Label

Spatial ${ }^{55}$

Metadata Element

<dcterms:spatial>

Definition

Spatial characteristics of the intellectual content of the resource.

Format of content Free text.

Geo-codes should preferably be formatted according to the DCMI Point

Encoding Scheme ${ }^{56}$, and the DCMI Box Encoding Scheme. ${ }^{57}$

\section{Obligation}

Recommended

Repeatable

Yes

Values (examples) <dcterms:spatial>Spain</dc: coverage</dcterms:spatial> <dcterms:spatial>name=Western Australia; northlimit=-

13.5; southlimit=-35.5; westlimit $=112.5$; east

limit $=129</$ dcterms: spatial>

<dcterms:spatial>http://data.logainm.ie/place/49237</d

cterms:spatial>

<dcterms:spatial>http://sws.geonames.org/3301443</dcte

rms:spatial>

<dcterms:spatial>http://id.worldcat.org/fast/1271105</

dcterms:spatial>

$55 \mathrm{http} / / /$ dublincore.org/documents/2012/06/14/dcmi-terms/?v=terms\#terms-spatial, last accessed 27

February 2015.

${ }^{56} \mathrm{http}: / /$ dublincore.org/documents/dcmi-point/, last accessed 14 August 2014

$57 \mathrm{http}: / /$ dublincore.org/documents/dcmi-box/, last accessed 14 August 2014. 


\section{Recommended Elements}

\section{Element refinement for <dc: coverage>}

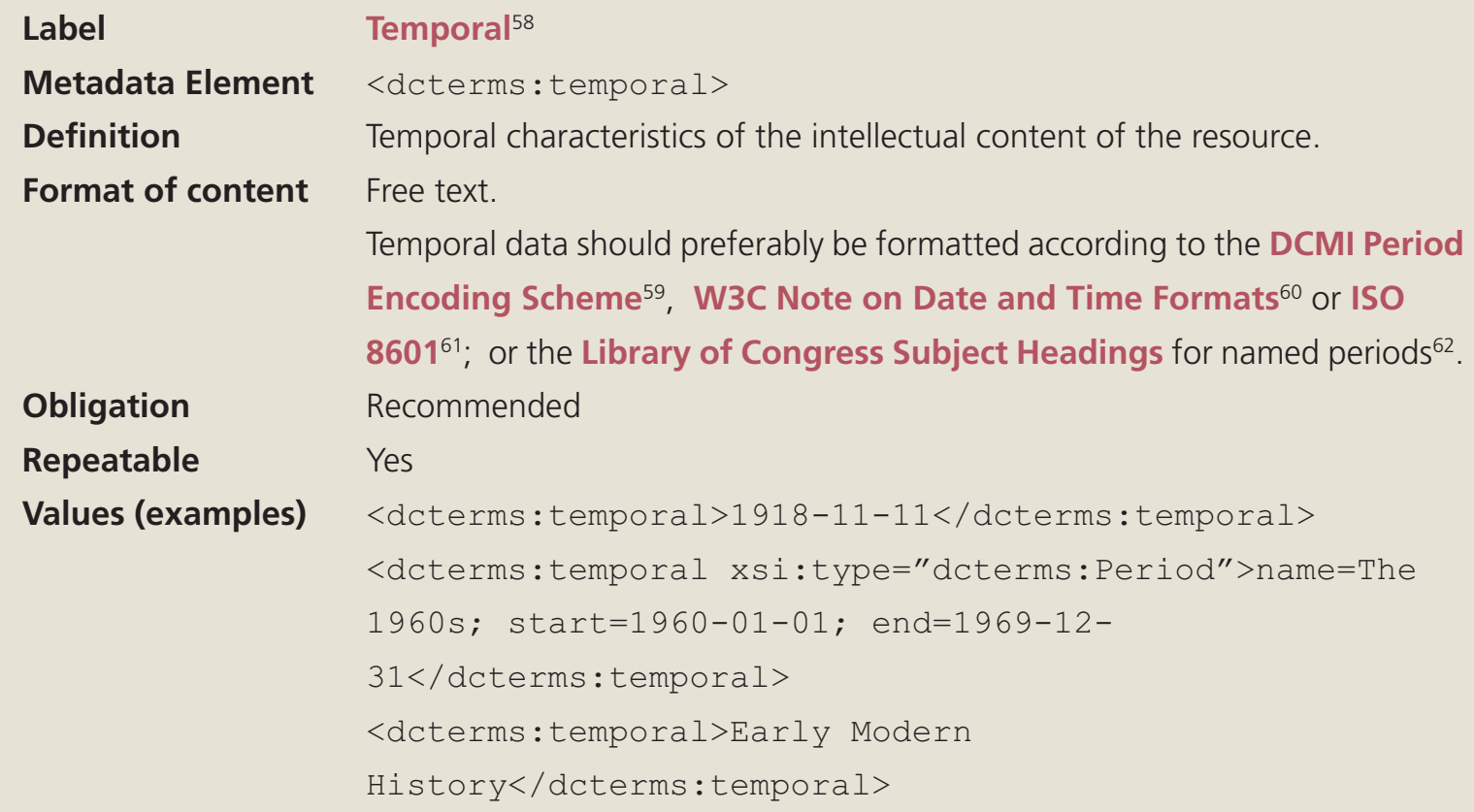

Label

\section{Subject ${ }^{63}$}

Metadata Element

$<$ dc: subject $>$

Definition

The topic of the resource.

Format of content Free text.

It is recommended to use a vocabulary or thesaurus that is appropriate to the record's subject. A suggested list is available on the DRI Vocabularies page ${ }^{64}$.

Obligation Recommended

\section{Repeatable} Yes

\section{Values (examples)}

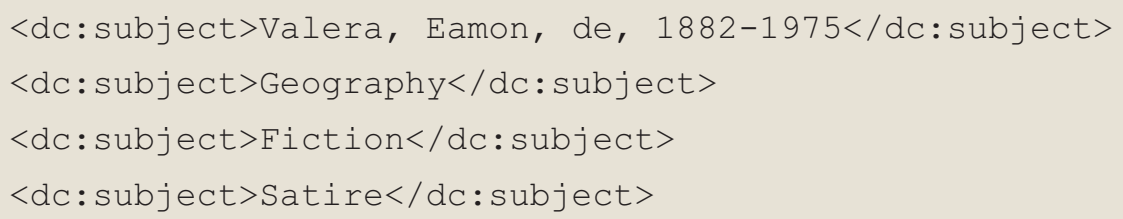

\footnotetext{
${ }^{58} \mathrm{http} / / /$ dublincore.org/documents/2012/06/14/dcmi-terms/?v=terms\#temporal, last accessed 27 February 2015.

${ }^{59} \mathrm{http}: / /$ dublincore.org/documents/dcmi-period/, last accessed 14 August 2014.

$60 \mathrm{http}: / / \mathrm{www} . \mathrm{w3}$.org/TR/NOTE-datetime, last accessed 14 August 2014.

${ }^{61} \mathrm{http}: / / \mathrm{www}$.iso.org/iso/home/standards/iso8601.htm, last accessed 14 August 2014.

62 http://id.loc.gov/authorities/subjects.html, last accessed 21 March 2014.

${ }^{63} \mathrm{http}: / /$ purl.org/dc/elements/1.1/subject, last accessed 14 August 2014.

${ }^{64} \mathrm{http}: / /$ dri.ie/vocabularies, last accessed 14 August 2014.
} 


\section{Recommended Elements}

\section{Element refinement for $\langle$ dc: subject $>$}

Label Depicted ${ }^{65}$

Metadata Element <marcrel:dpc>

Definition Use for an entity depicted or portrayed in a work, particularly in a work of art.

Format of content Free text.

It is recommended to use a vocabulary or thesaurus that is appropriate to the record's subject. A suggested list is available on the DRI Vocabularies page ${ }^{66}$.

Obligation Recommended

Repeatable Yes

Values (examples) <marcrel:dpc>Valera, Eamon, de, 1882-1975</marcrel:dpc> $<$ marcrel:dpc>The River Liffey</marcrel:dpc $>$

65 http://lcweb2.loc.gov/diglib/loc.terms/relators/dc-contributor.html, last accessed 13 February 2015

66 http://dri.ie/vocabularies, last accessed 14 August 2014. 


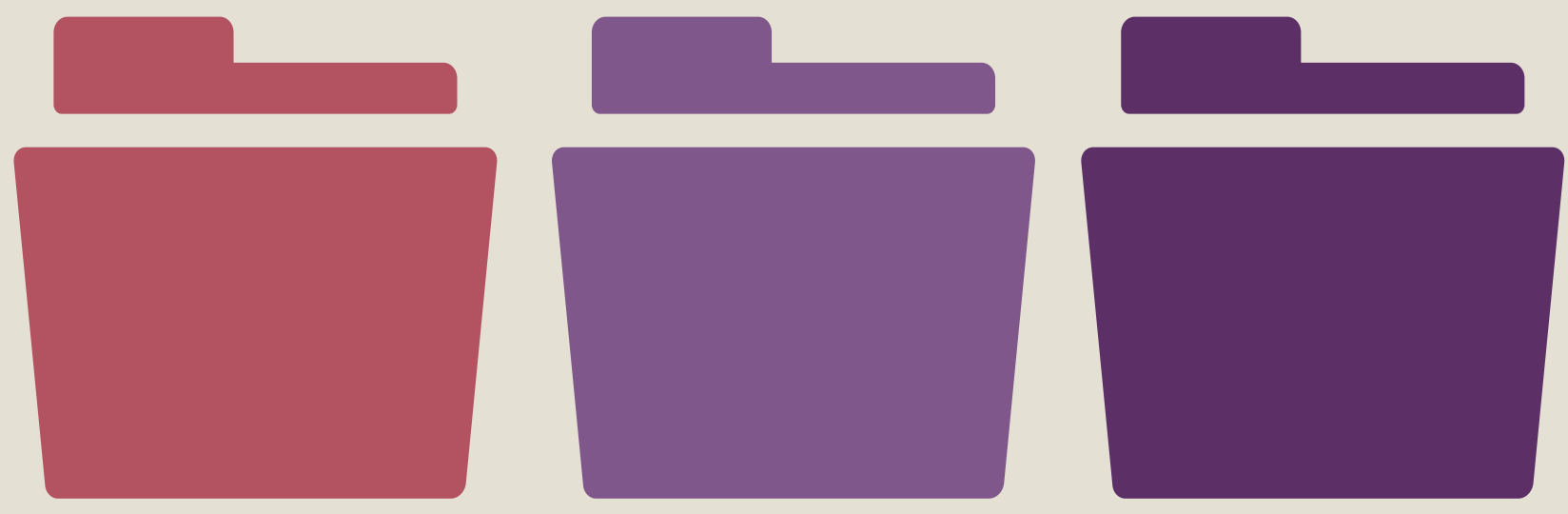

wuw.dri.ie 